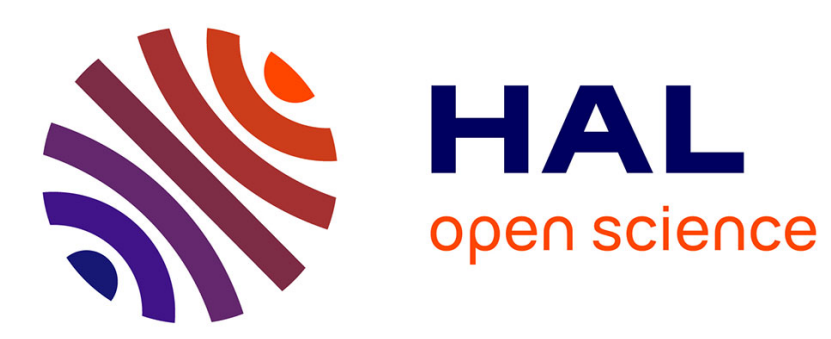

\title{
Impact of hydroxypropylguars on the early age hydration of Portland cement
}

\author{
Thomas Poinot, Alexandre Govin, Philippe Grosseau
}

\section{To cite this version:}

Thomas Poinot, Alexandre Govin, Philippe Grosseau. Impact of hydroxypropylguars on the early age hydration of Portland cement. Cement and Concrete Research, 2013, 44, pp.69-76. 10.1016/j.cemconres.2012.10.010 . hal-00758284v2

\section{HAL Id: hal-00758284 \\ https://hal.science/hal-00758284v2}

Submitted on 15 Feb 2013

HAL is a multi-disciplinary open access archive for the deposit and dissemination of scientific research documents, whether they are published or not. The documents may come from teaching and research institutions in France or abroad, or from public or private research centers.
L'archive ouverte pluridisciplinaire HAL, est destinée au dépôt et à la diffusion de documents scientifiques de niveau recherche, publiés ou non, émanant des établissements d'enseignement et de recherche français ou étrangers, des laboratoires publics ou privés. 


\section{Impact of hydroxypropylguars on the early age hydration}

\section{2 of portland cement}

3

4

5 Thomas Poinot - Alexandre Govin ${ }^{*}$ — Philippe Grosseau

6

7 Ecole Nationale Supérieure des Mines, SPIN-EMSE, CNRS:FRE3312, LPMG, F-42023

8 Saint-Etienne, France

9

10

11 * Corresponding author: Tel: +33477420253

12
E-mail address: govin@emse.fr 
14 Hydroxypropylguars (HPG) are used as admixtures in factory-made mortars. These molecules

15 present water retention properties comparable to those obtained with commonly used 16 cellulosic water-retaining agent.

17 The influence of HPG on cement hydration was investigated in order to improve 18 understanding on the delayed effect induced by polysaccharides. Hydration kinetics were 19 characterized by means of conductivity and isothermal calorimetry measurements. The 20 influence of polymer concentration and predissolution was studied. A weak influence of HPG 21 on the germination of hydrates was observed. In contrast, HPG induced a significant decrease 22 in the hydrates growth rate. Strong effects of the polymer concentration and predissolution 23 were noticed too. From these results, we supported the hypothesis that HPG adsorption on 24 hydrated phases via polar interactions should be responsible for the delayed effect observed. water retention $(C)$ 


\section{Introduction}

Traditionally, mortars are based on a mixture of sand, a binder such as cement or lime, and water. Nowadays, modern factory-made mortars are complex materials, in which are added some kinds of admixtures used to exhibit various properties, from the fresh state to the hardened material.

Polysaccharides are one of these admixtures. They are frequently introduced into mortar formulations in order to improve water retention capacity of the freshly-mixed materials, which enhances cement hydration and adhesion to the substrate [1-4]. These products are also expected to act as viscosity-enhancing admixtures to prevent segregation and thus improve the homogeneity and workability of the mortar [5-8].

Among all polysaccharides, Cellulose Ethers (CE) are the most widely used when high water retention capacity is expected. Nevertheless, HydroxyPropylGuars (HPG) were recently presented as a promising new class of water-retaining agent [9]. HPG are already used in various industrial fields, such as textile printing, oil production or paper manufacturing, due to their thickening effect [10]. HPG were also the subject of some patents as admixture for mortars.

The effect of saccharides has been largely studied these fifty last years, in particular from a cement hydration delay point of view. In the first time, the delayed effect of monosaccharides was investigated [11-19]. It appears that sugars could be adsorbed to cement phases by a chelation process. It can thereby form a temporary barrier to further hydration. In broad agreement with Young [11], Thomas and Birchall [12] proposed that sugars would be able to poison the surfaces of the $\mathrm{CH}$ and $\mathrm{CSH}$ by complexation onto these phases, which inhibit their growth and therefore would be responsible for the delay observed. According to Taplin 
54 [13], sugars could bind to the cement phases if they have a $\mathrm{HO}-\mathrm{C}=\mathrm{O}$ group, or it could be

55 formed in alkaline media, such as cement paste, by hydrolyze [14].

Then, due to the use of polysaccharides in modern factory-made mortars, interactions between polysaccharides and cement have been reported recently. It is established that polysaccharides induce a more or less important delay of Portland cement hydration [20-25], which depends on the nature of the polysaccharide [26]. Pourchez et al. [27, 28] have established a mechanism of interaction between $\mathrm{CE}$ and cement.

However, HPG have received scant attention by the academic community although they are already used industrially. As far as we know, only Izaguirre et al. [29] was interested on the impact of HPG, but in lime-based mortars. Thus, the aim of this work is to study the influence of HPG on the Portland cement hydration kinetics at early age.

Firstly, the water-retaining effect induced by the HPG in Portland cement-based mortars will be checked. Secondly, cement hydration kinetics in the presence of HPG will be presented. Hydration kinetics have been monitored by conductivity and isothermal calorimetry measurements. Finally, a special focus on the influence of the polymer predissolution has been performed.

\section{Materials}

\subsection{Mineral product}

The investigated ordinary Portland cement (OPC) was a CEM I 52.5 R CE CP2 NF type cement according to the EN 197-1 standard. Its chemical and phase compositions are given in Table 1. Oxide composition was determined by X-ray fluorescence spectroscopy (SRS3400, Bruker-AXS). XRD analysis (D5000, Siemens) also allowed quantifying the phase composition of the given cement by means of Rietveld refinement method (Siroquant V2.5 
77 software). 
Table 1: Chemical and phase compositions of the investigated cement.

\begin{tabular}{|cc|cc|cc|}
\hline \multicolumn{3}{|c|}{ Chemical composition (\% wt) } & \multicolumn{2}{c|}{ Phase composition (\% wt) } \\
\hline Oxides & XRF & Oxides & XRF & Phases & XRD (Rietveld) \\
\hline $\mathrm{CaO}$ & $66.1 \pm 1.2$ & $\mathrm{TiO}_{2}$ & $0.24 \pm 0.01$ & $\mathrm{C}_{3} \mathrm{~S}$ & $73.0 \pm 0.53$ \\
$\mathrm{SiO}_{2}$ & $20.2 \pm 0.4$ & $\mathrm{P}_{2} \mathrm{O}_{5}$ & $0.05 \pm 0.01$ & $\mathrm{C}_{2} \mathrm{~S}$ & $12.7 \pm 0.50$ \\
$\mathrm{Al}_{2} \mathrm{O}_{3}$ & $4.8 \pm 0.1$ & $\mathrm{MnO}$ & $0.04 \pm 0.00$ & $\mathrm{C}_{3} \mathrm{~A}$ & $4.2 \pm 0.18$ \\
$\mathrm{SO}_{3}$ & $3.5 \pm 0.2$ & $\mathrm{~K} 2 \mathrm{O}$ & $0.01 \pm 0.01$ & $\mathrm{C}_{4} \mathrm{AF}$ & $6.1 \pm 0.22$ \\
$\mathrm{Fe}_{2} \mathrm{O}_{3}$ & $2.9 \pm 0.1$ & $\mathrm{LOI}$ & $2.2 \pm 0.2$ & Gypsum & $1.7 \pm 0.15$ \\
$\mathrm{MgO}$ & $1.11 \pm 0.02$ & & & Anhydrite & $2.3 \pm 0.28$ \\
\hline
\end{tabular}

\subsection{Organic admixtures}

81 Guar gum is a polysaccharide extracted from the seed endosperm of Cyamopsis

82 tetragonolobus, a native plant from India. This is a galactomannan consisting of a (1-4)-

83 linked $\beta$-D-mannopyranose backbone, with random branchpoints of galactose via an $\alpha-(1-6)$

84 linkage [30] (Fig. 1a). The ratio of mannose to galactose is about 1.8. Unlike the

85 manufacturing of cellulose, the extraction does not require chemical process, but a thermo-

86 mechanical one. So, guar gum is produced without producing any effluent. Moreover, because

87 of the presence of hydroxyl groups in its structure, guar gum exhibits a high chemical

88 reactivity and is soluble in cold water. Thus, the chemical modification of this polysaccharide

89 does not require hard reaction conditions of temperature and pressure, does not generate large

90 quantity of by-products and needs weak purification procedure [31].

91 HPG are obtained from the native guar gum via an irreversible nucleophilic substitution,

92 using propylene oxide in the presence of an alkaline catalyst (Fig. 1b). Table 2 gives a 93 qualitative description of the six HPG samples from Lamberti S.p.A which were studied. All 94 the samples have similar molecular weight. The only difference between HPG 1, 2 and 3 is 
95 the Degree of Substitution (DS). The only difference between HPG 4, 5 and 6 is the presence

96 of additional substitution (short or long alkyl chains).

97 In order to compare with classical polysaccharide admixtures, three CE were also tested

98 (Table 2): two HydroxyPropylMethyl Cellulose (HPMC) named HPMC1 and HPMC2, and 99 one HydroxyEthyl Cellulose (HEC).
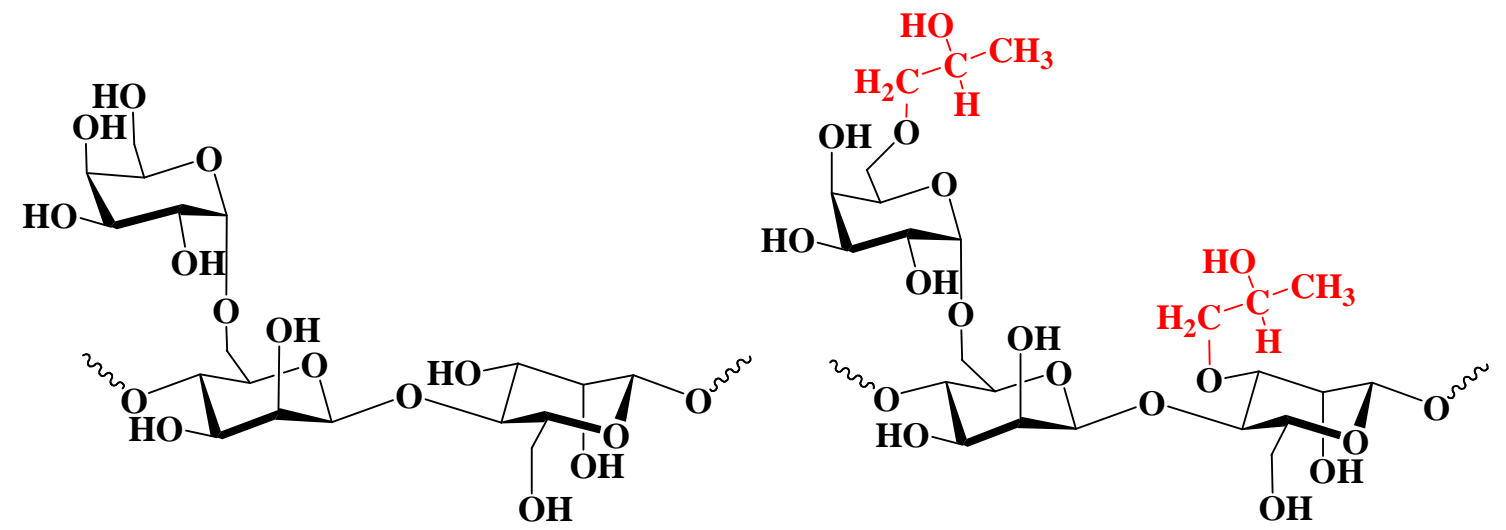

Fig. 1: Molecular structure of native guar gum (a) and hydroxypropylguar (b).

Table 2: Qualitative description of the admixtures used.

\begin{tabular}{|c|ccc|}
\hline Admixtures & DS & Viscosity & Additional substitution \\
\hline HPG 1 & Low & High & - \\
HPG 2 & Medium & Medium & - \\
HPG 3 & High & Medium & - \\
HPG 4 & High & Low & - \\
HPG 5 & High & Medium & Shorter alkyl chain \\
HPG 6 & High & Medium & Longer alkyl chain \\
\hline HPMC 1 & High & Very low & - \\
HPMC 2 & High & Very high & - \\
HEC & High & Very low & - \\
\hline
\end{tabular}




\section{Experimental methods of investigation}

\subsection{Water retention measurements}

107 Water retention capacity of mortars was characterized according to ASTM C1506-09 standard

108 [32]. This test is based on a measurement of the removed water after depression and was

109 previously described by Patural et al. [3]. Water retention, noted WR, was calculated using

110 the following equation:

$111 \quad W R(\%)=\frac{W_{0}-W_{1}}{W_{0}} \times 100$

$112 \mathrm{~W}_{0}$ represents the initial mass of mixing water; $\mathrm{W}_{1}$ is the loss of water mass after aspiration.

113 Mortars were prepared according to the following mixture proportions: $30 \%$ of cement, $65 \%$

114 of sand and $5 \%$ of limestone filler (by weight). This mixture design was adapted from the

115 CEReM (european consortium for study and research on mortars) mortars formulation [3].

116 Admixture amount $(0.3 \mathrm{wt} \%)$ was in addition to the total dry mixture (i.e. cement, sand and

117 filler). Dry mixture was blended in a shaker (Turbula, Wab) for $15 \mathrm{~min}$. Deionized water was

118 added in order to obtain a water to cement ratio $\mathrm{W} / \mathrm{C}=1$. Mixing procedure was in

119 accordance with EN 196-1 [33]. All tests were carried out in triplicate and at controlled

120 temperature of $23^{\circ} \mathrm{C}$ because water retention is temperature-dependent. A control test was

121 performed with a mortar without admixture. 


\subsection{Characterization of the cement hydration delay}

\subsubsection{Conductivity measurements on diluted suspensions}

124 Characterization of the delay induced by the studied polymers on the cement hydration was

125 performed by conductivity measurements. This method appears as a powerful and

126 reproducible tool to monitor the hydration kinetics [34,35].

127 Conductivity measurements could be achieved in lime suspension. This allows obtaining

128 hydration kinetics close to that observed in cement pastes, in spite of a high liquid to solid

129 weight ratio (noted L/S). Nevertheless, monitoring hydration kinetics in an artificial system of

130 lime water is complicated because the dissolution rate of calcium from the cement could be

131 modified due to the initial high concentration of calcium ions in solution. Thus, conductivity

132 curves were interpreted according to the explanation proposed by Comparet et al. [36]. As

133 soon as cement was put in contact with liquid, the electrical conductivity increased as a

134 consequence of the dissolution of the anhydrous phases. Then, germination of hydrates on the

135 grain surface leads to a period, called "low conductivity increasing period", where the

136 conductivity evolves weakly. Conductivity then accelerated more quickly. The conductimetric

137 slope is related to the growth rate of the hydration products. Meanwhile, cement dissolution

138 still continued. The conductivity increased to the critical supersaturation point with respect to

139 portlandite and decreased rapidly due to its precipitation. Thus, an electrical conductivity drop

140 is caused by the portlandite precipitation. This phenomenon was used to determine the

141 hydration delay. Therefore, in this study, the portlandite precipitation time (noted $t_{\mathrm{CH}}$ ) is a

142 benchmark to classify and to quantify the relative retardation ability of admixtures on cement

143 hydration.

144 Experiments were performed in diluted suspensions, thermostated at $25^{\circ} \mathrm{C}$ and continuously

145 stirred. Each experiment was carried out in triplicate. The liquid to solid weight ratio (L/S)

146 used was equal to 20. Polymer to cement weight ratios (P/C) equal to $0.5,1.0,1.5$ and $2.0 \%$ 
147 were studied. Cement and admixture powders were blended in a shaker (Turbula, Wab) for 10

148 min before contact with the liquid phase. The liquid used was a $20 \mathrm{mM}$ lime solution or

149 deionized water. The control used was the neat cement.

\subsubsection{Isothermal calorimetry on cement pastes}

151 Calorimetry is another technique useful to characterize the exothermic hydration process of cement. The hydration process can be followed continuously at realistic water/cement ratios

153 (W/C) in situ and aims at giving an indication of the overall rate of reaction. Thus, 154 calorimetry can be used as a complementary method to conductivity in order to monitor the

155 kinetics of cement hydration and to observe hydration delay induced by retarders [37].

156 The tests were performed with an isothermal calorimeter $(\mathrm{C} 80$, Setaram $)$ at $25^{\circ} \mathrm{C}$. The weight 157 ratios used were $\mathrm{W} / \mathrm{C}=0.4$, with deionized water, and $\mathrm{P} / \mathrm{C}=0.3 \%$. Ex-situ mixing was 158 preferred to in-situ mixing to improve the homogeneity of the sample, and thus 159 reproducibility. Mixing procedure, with $100 \mathrm{~g}$ of cement, was in accordance with standard EN $160196-1$ [33]. 10 min after the beginning of the batch, about $2 \mathrm{~g}$ of paste are introduced in the 161 calorimeter. The control used was the neat cement.

\subsubsection{Predissolution of the admixture}

163 The influence of the polymer predissolution was studied by means of conductivity and

164 isothermal calorimetry measurements. Admixtures were previously dissolved in the liquid 165 phase, deionized water or $20 \mathrm{mM}$ lime solution, for $24 \mathrm{~h}$ by magnetic stirring. Then, cement 166 was added.

167 In case of conductivity experiments, the effect of the predissolution has been highlighted by

168 calculating the increase percentage in the portlandite precipitation time $\mathrm{t}_{\mathrm{CH}}$ as followed (in 169 gray in Fig. 10): 


\subsection{Calcium binding capacity}

172 The ability of HPG and also sugars (sucrose which is known to complex calcium ions,

173 galactose and mannose which constitute HPG's molecule) to form complexes with calcium

174 ions was studied. Sugars are valuable insights in order to compare the behavior of HPG and to

175 validate the relevance of this protocol, developed by Thomas and Birchall [12].

176 Each sample ( $2 \mathrm{~g}$ per liter) was introduced into a volume of water (1L) containing a large 177 excess of solid lime ( $6 \mathrm{~g}$ per liter). After 48 hours of stirring at a controlled temperature of $17823^{\circ} \mathrm{C}$, the suspension was filtered through a $0.7 \mu \mathrm{m}$ glass fiber filter. The filtrates were diluted 179 and acidified. Then, a quantification of the calcium ion content by ionic chromatography was 180 performed on a Dionex apparatus composed of a GP 50 gradient pump, a CS 12A cation181 exchange column and a CD 20 conductometric detector. The eluent was a solution of 182 metasulfonic acid at $20 \mathrm{mM}$ with isocratic mode. The flow was fixed at $1 \mathrm{~mL} / \mathrm{min}$. The results 183 correspond to an average of 3 experiments.

184 As the solid calcium hydroxide is in large excess, calcium ions consumed by complexation do 185 not affect the "stock" of calcium ions in solution, which thus remains equal to $23 \mathrm{mM}$ during 186 the experiment. However, once the filtrate diluted and acidified, the complexes are destroyed, 187 thus freeing the complexed calcium ions. So, if the calcium concentration is about $23 \mathrm{mM}$ 188 (solubility of lime), no significant complexation has taken place. Instead, a calcium concentration above $23 \mathrm{mM}$ indicates a significant complexation of calcium ions. 
191 HPG absorb in the ultraviolet as evidenced by the absorption spectra (Fig. 2a), and the concentration of HPG in solution is proportional to the absorbance at the maximum of the band (266 nm) as shown in Fig. 2 b.
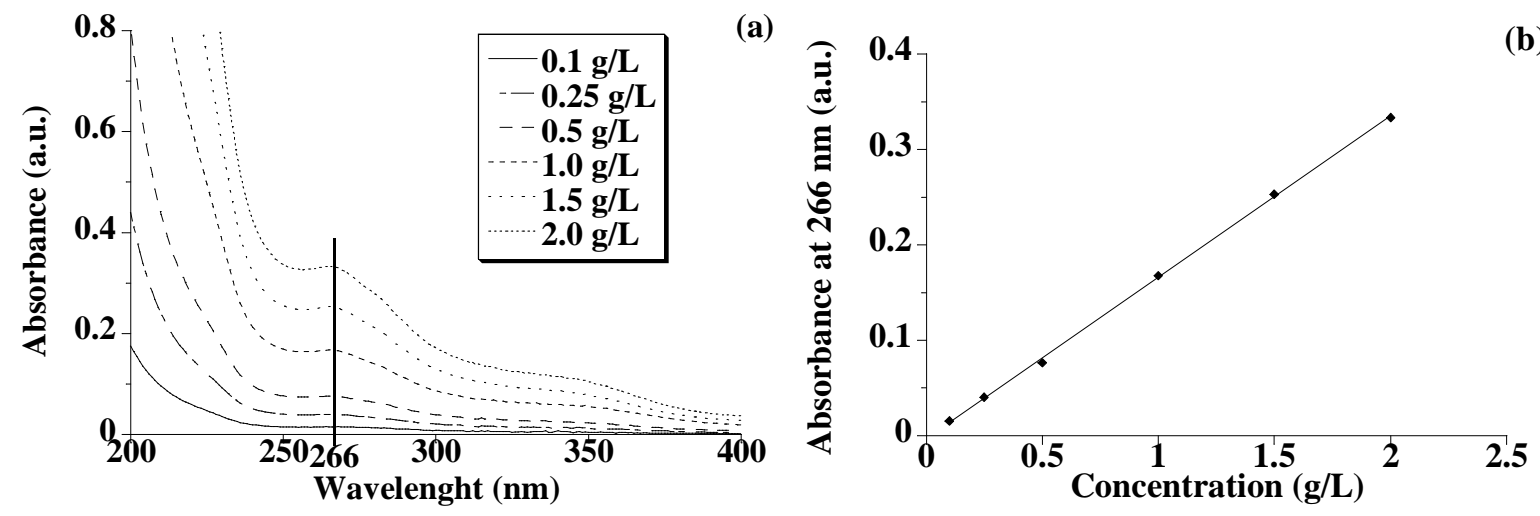

Fig. 2: UV absorption spectra (a) and absorption at $266 \mathrm{~nm}$ vs. concentration (b) for HPG in water

196

197

The dissolution process was monitored by acquisition of UV-Vis absorption spectra. The procedure was the following: a dispersion of HPG (final concentration: $2 \mathrm{~g} . \mathrm{L}^{-1}$ ) in deionized water or $20 \mathrm{mM}$ lime solution was prepared in a sealed reactor (1L of solution) thermostated at $25^{\circ} \mathrm{C}$. HPG was introduced through a sieve in order to have a good dispersion of the sample into the vortex created by the mechanic stirrer. Thus, the aggregation of particles was minimized and a homogeneous polymer solution was produced. The experiment was done under continuous flow of nitrogen to avoid carbonation of lime. At different times, an aliquot of approximately $5 \mathrm{~mL}$ was taken from the batch solution and centrifuged by means of a micro-centrifuge (Eppendorf MiniSpin Plus, $14500 \mathrm{rpm}$ ) for $5 \mathrm{~min}$ in order to remove undissolved particles. The supernatant was collected and homogenized by vortex-stirring. The absorbance of this solution was measured between 200 and $400 \mathrm{~nm}$ using an UV/Visible spectrophotometer (Cary 300 Scan, Varian). A degree of progress of the dissolution reaction $\lambda(t)$ was used, which is equal to the absorption at time $t$ divided by the absorption at the end 
of the dissolution reaction (i.e. $24 \mathrm{~h}$ ). This number is adimensional and its value is between 0

210 and 1.

\section{Results and discussions}

\subsection{Impact of HPG on water retention in fresh mortar}

213 Water retention is a very sensitive mortar property. Indeed, it must be important enough to not

214 disturb the hydration of the cement. It also limits the absorption of the mixing water by the 215 substrate and thus provides good mechanical and adhesive properties to the mortar.

DTU 26.1 [38] specifies three classes of water retention of a fresh mortar. The first one

217 represents mortars which water retention is lower than $86 \%$; they belong to the low water 218 retention category. The second class (intermediate water retention) corresponds to values 219 ranging from $86 \%$ to $94 \%$. The last one is defined by water retention higher than $94 \%$. This 220 class is related to strong water retention mortar and is desired by formulators of industrial 221 mortars.

222 Water retention capacity of the studied mortars according to the admixture used is shown in 223 Fig. 3. With this formulation, mortars containing HPG 2 to 6 and HPMC 2 could be 224 considered as high WR capacity according to the DTU 26.1. Mortars containing HPG 1, 225 HPMC 1 and HEC are in the intermediate category.

226 Thus, HPG improve considerably the water retention capacity of the mortar compared to the 227 control without water-retention admixture, as announced by Plank [9]. In addition, the results 228 are quite comparable to those obtained with the $\mathrm{CE}$ of reference.

229 Therefore, HPG can be considered as promising water-retention agents for dry-mix Portland 230 cement-based mortars. 


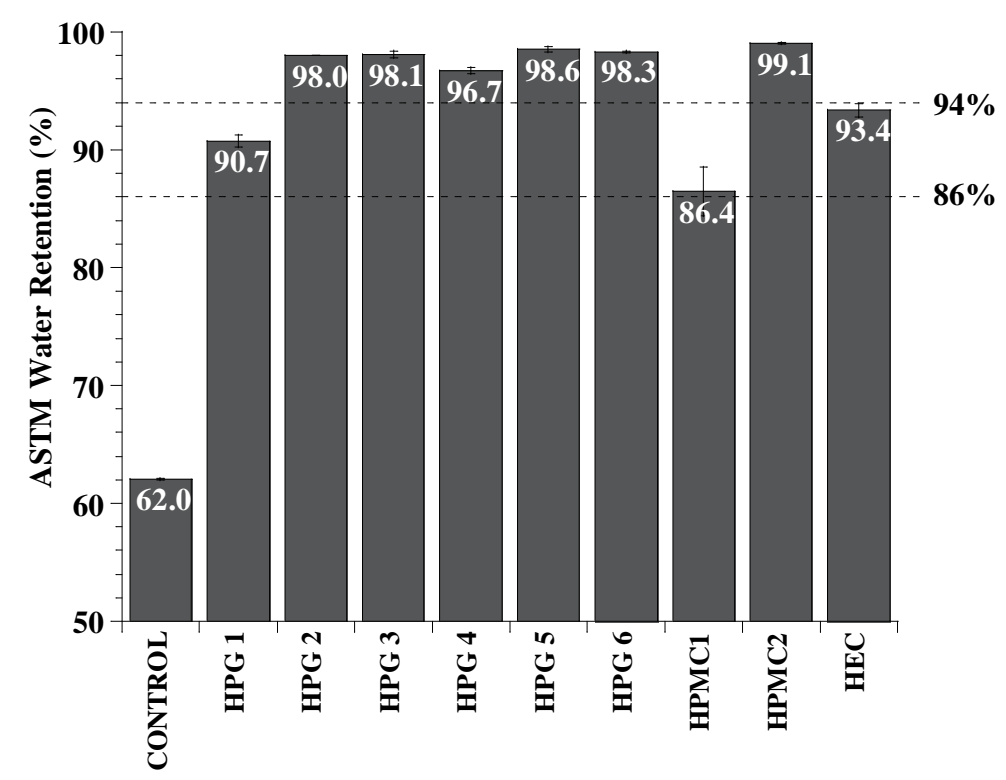

Fig. 3: Water retention capacity of studied mortars with $0.3 \%$ w.t. of admixture.

\subsection{Impact of HPG on hydration kinetics of cement}

235 The delayed effect of HPG on cement hydration kinetics was monitored by conductivity in a $23620 \mathrm{mM}$ lime solution, for ratios $\mathrm{L} / \mathrm{S}=20$ and $\mathrm{P} / \mathrm{C}=2 \%$. To have a clear and readable 237 analysis, all the conductimetric curves will not be presented on the same figure. Thus, Table 3 238 regroups the conductimetric data obtained (i.e. portlandite precipitation times, delays 239 compared to the control and conductimetric slopes). Fig. 4 presents the influence of the DS on 240 the conductimetric curves by studying HPG 1,2 and 3 which are the same molecules, except 241 the DS (DSHPG1>DSHPG2>DSHPG3). The influence of the alkyl substitution was studied 242 by comparison of HPG 4, 5 and 6 (see Table 2). The conductimetric curves obtained are 243 shown 
Table 3: Comparison of conductimetric data according to the admixtures studied

\begin{tabular}{|c|c|c|c|c|c|c|c|c|c|c|}
\hline Admixture & Without & HPG 1 & HPG 2 & HPG 3 & HPG 4 & HPG 5 & HPG 6 & HPMC 1 & HPMC 2 & HEC \\
\hline $\begin{array}{c}\text { Portlandite } \\
\text { precipitation } \\
\text { time (min) }\end{array}$ & $\begin{array}{r}252 \\
\pm 0\end{array}$ & $\begin{array}{l}1083 \\
\pm 13\end{array}$ & $\begin{array}{r}786 \\
\pm 27 \\
\end{array}$ & $\begin{array}{r}611 \\
\pm 16 \\
\end{array}$ & $\begin{array}{l}478 \\
\pm 9\end{array}$ & $\begin{array}{r}432 \\
\pm 7 \\
\end{array}$ & $\begin{array}{l}420 \\
\pm 9 \\
\end{array}$ & $\begin{array}{l}366 \\
\pm 3\end{array}$ & $\begin{array}{r}354 \\
\pm 9 \\
\end{array}$ & $\begin{array}{l}1273 \\
\pm 15 \\
\end{array}$ \\
\hline $\begin{array}{c}\text { Delay compared } \\
\text { to the control } \\
(\%)\end{array}$ & I & 329 & 212 & 142 & 89 & 71 & 66 & 45 & 40 & 405 \\
\hline $\begin{array}{l}\text { Conductimetric } \\
\text { slope } \\
\left(\mu \mathrm{S} . \mathrm{cm}^{-1} \cdot \mathrm{min}^{-1}\right) \\
\end{array}$ & $\begin{array}{r}19.6 \\
\pm 1.5 \\
\end{array}$ & $\begin{array}{c}3.3 \\
\pm 0.4\end{array}$ & $\begin{array}{c}5.0 \\
\pm 0.5\end{array}$ & $\begin{array}{l}7.0 \\
\pm 0.5\end{array}$ & $\begin{array}{l}9.6 \\
\pm 0.8\end{array}$ & $\begin{array}{r}11.4 \\
\pm 0.9\end{array}$ & $\begin{array}{r}11.4 \\
\pm 0.9\end{array}$ & $\begin{array}{r}13.5 \\
\pm 1.0\end{array}$ & $\begin{array}{r}13.5 \\
\pm 1.7\end{array}$ & $\begin{array}{c}3.3 \\
\pm 0.0\end{array}$ \\
\hline
\end{tabular}
246
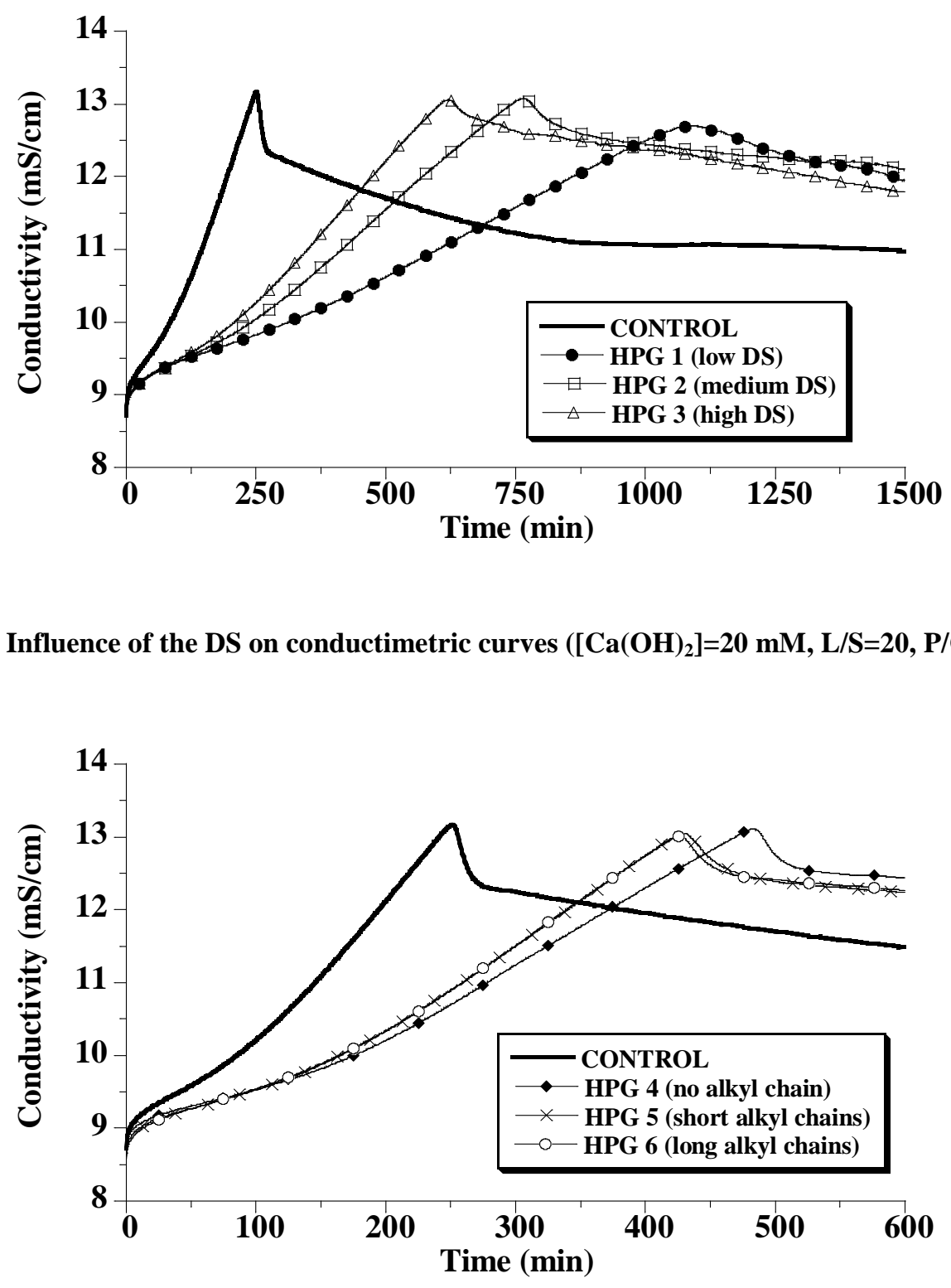

250 Fig. 5: Influence of alkyl substitution on conductimetric curves $\left(\left[\mathrm{Ca}(\mathrm{OH})_{2}\right]=20 \mathrm{mM}, \mathrm{L} / \mathrm{S}=\mathbf{2 0}, \mathrm{P} / \mathrm{C}=\mathbf{2 \%}\right)$. 
252 The conductimetric data (Table 3) highlights the impact of HPG on the kinetics of hydration.

253 By focusing on the portlandite precipitation time (conductivity drop) and delays, it appears a 254 wide range of delays induced by the admixtures studied. HPG 5 and 6 exhibit superposed 255 conductimetric curves and the weaker delay $(+71 \%$ and $+66 \%$ respectively). The most 256 important delay is observed for HPG $1(+329 \%)$. It also appears that delays induced by HPG 257 are between those obtained for the CE studied (+40\% to $+405 \%)$.

258 Some polysaccharides (dextrines for example [26]) or other admixtures (setting retarding 259 admixtures such as sugars [19], sodium gluconate [39] or some superplasticizers [36]) induce 260 a blocking effect or an inhibition of the hydration. Here, from the shape of the conductimetric 261 curves obtained, HPG involve a small increase in the duration of the "low conductivity 262 increasing period". Therefore, this indicates a weak influence of the HPG on the germination 263 of cement hydrates. The delay of portlandite precipitation time seems to be mainly due to a 264 slope decrease (Table 3). Indeed, the slope obtained with the control is almost six times 265 higher than that obtained for HPG 1. The slope of the conductimetric curve is linked to the 266 growth rate of the hydrated cement phases. HPG seem to act preferentially on the growth of 267 hydrates phases, rather than on their germination. This could explain the delays observed and 268 is in agreement with results obtained with CE [40].

269 In addition, delay increases when DS decreases (Fig. 4). Nevertheless, the alkyl substitution 270 seems to have a slight effect (Fig. 5) because the delay slightly decreases in the presence of 271 alkyl chains. The effect of the chain length is negligible.

\subsubsection{Calcium binding capacity}

273 The calcium complexation is often advanced as assumption to explain the effect of retarders 274 [41]. It seemed important to check if HPG complex with calcium ions. The calcium binding 275 capacity at alkaline $\mathrm{pH}$ of the 6 HPG and 3 sugars were conducted and the results are 
presented in Fig. 6. It appears clearly that the complexation of calcium ions by HPG is null or

277 very weak, like with CE [42]. Indeed, the value of calcium ions concentration found for the 278 HPG samples was close to the reference sample and is only due to the lime solubility. Instead, 279 sugars studied present higher calcium ion concentration due to a greater binding capacity, 280 which is coherent according to the data of the literature [12,42]. Therefore, calcium ion 281 complexation is clearly not responsible for the delay of cement hydration induced by HPG.

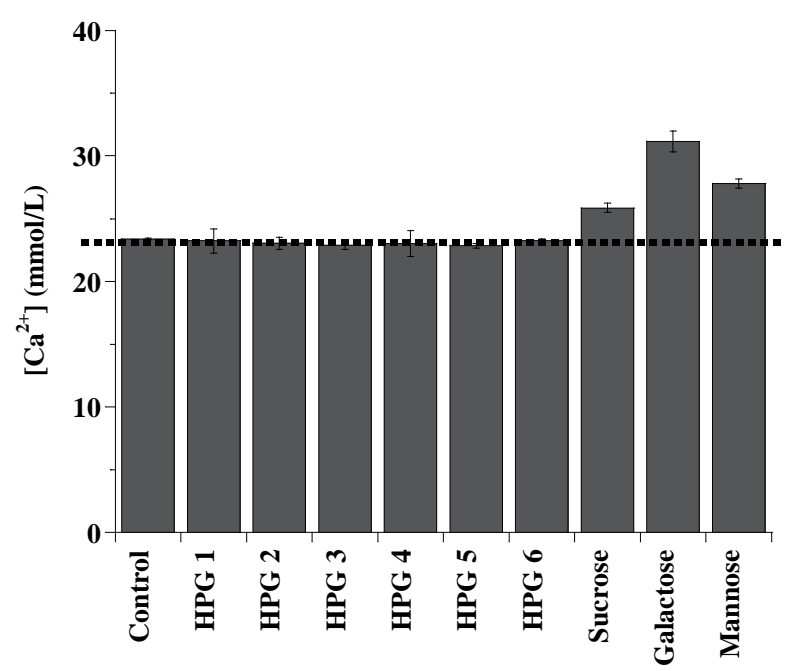

Fig. 6: Calcium binding capacity of HPG and monosaccharides.

\subsubsection{Influence of polymer concentration}

The influence of the amount of polymer is studied by conductivity in $20 \mathrm{mM}$ lime solution by varying P/C ratio with a constant L/S ratio (equal to 20) for each HPG. The effect of polymer concentration is considerable and results in a drastic decrease in the slope (Fig. 7). Thus, a small increase in the amount of polymer leads to a huge increase in the portlandite precipitation time, and so in the delay of hydration. Fig. 8 presents the portlandite precipitation time for each polymer and concentration. The effect of the concentration is

291 similar whatever the molecule. For each polymer, the more the concentration increases, the 292 more the delay increases. As the retarding effect is effective at very low HPG concentrations, 293 it confirms that calcium complexation cannot be responsible for the delay mechanism. 
294 It is generally admitted that cement hydration delay induced by admixtures is due to 295 adsorption of these molecules to surfaces of the hydrating cement particles and/or surfaces of 296 hydration products $[41,43]$. The concentration dependent behavior of the delay suggests also 297 that HPG delay cement hydration via adsorption on the cement phases.

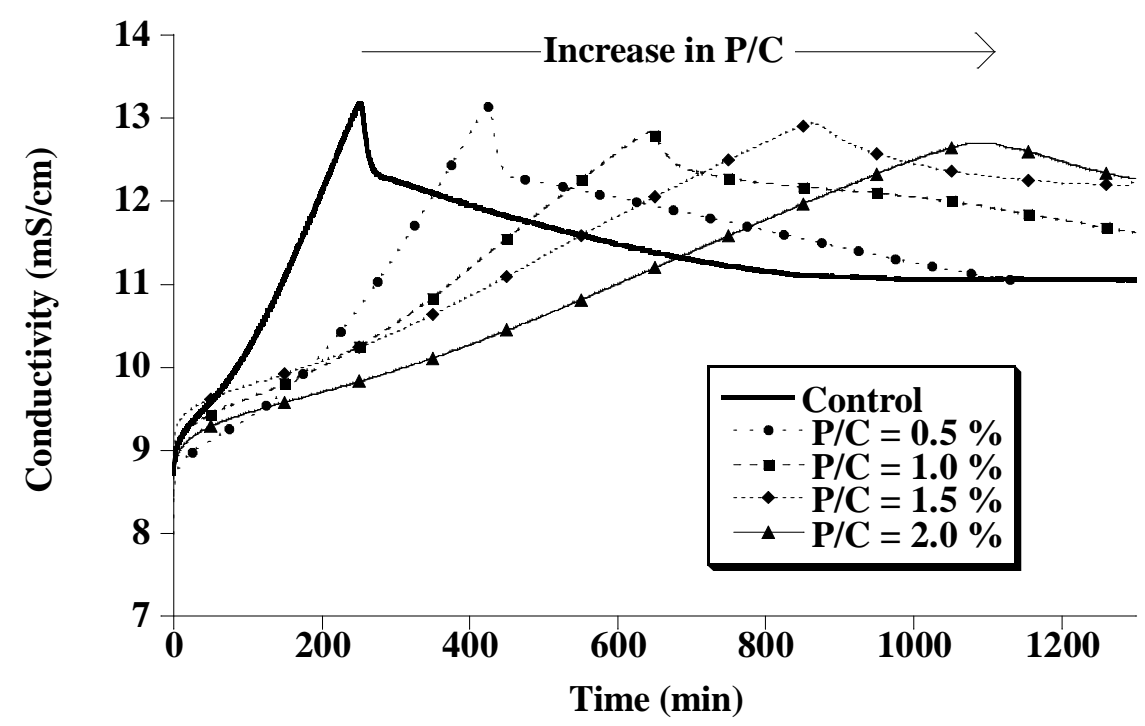

Fig.7: Conductimetric curves of cement admixed with HPG 1 in lime solution according to the P/C ratio $\left(\left[\mathrm{Ca}(\mathrm{OH})_{2}\right]=20 \mathrm{mM}, \mathrm{L} / \mathrm{S}=\mathbf{2 0}\right)$.

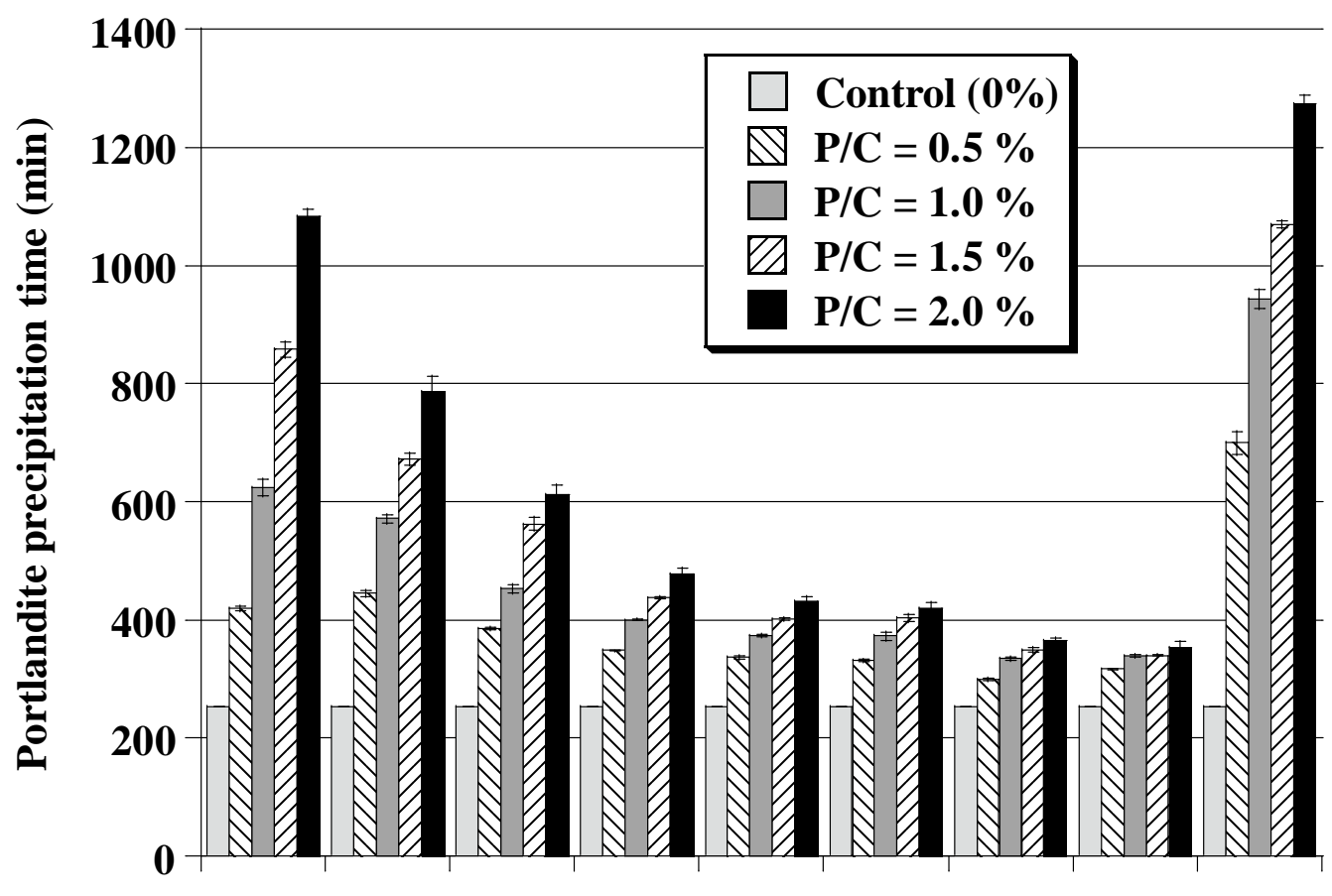

Fig. 8: Influence of admixtures concentrations on portlandite precipitation time. 
The mechanism responsible for the delay induced by CE is the adsorption of the molecule on

304 the hydrate cement phases. Indeed, Pourchez et al. have shown evidence of the adsorption of $305 \mathrm{CE}$ on calcium hydroaluminates [44] and $\mathrm{CSH} / \mathrm{CH}$ [40]. Polysaccharides are molecules which 306 contain a lot of polar functional groups (-OH). Therefore, strong interactions, through 307 electrostatic forces and hydrogen-bonding, can occur between polysaccharides and the highly 308 polar hydrated phases [43]. The relationship between adsorption and retardation was 309 previously shown $[25,40]$. It results that the higher the substituent content is, the weaker the 310 retardation ability is, because of lower amount of free hydroxyls and so lower adsorption 311 ability.

312 For HPG, the phenomena could be very close, due to the similarity of the molecules used, in 313 particular the high content of hydroxyl groups. Wang et al. [45,46] have shown that the 314 adsorption mechanism of galactomannose polysaccharides at solid-liquid interfaces involves 315 strong hydrogen bonding. Results obtained are in broad agreement with the relationship 316 between adsorption and retardation described above. Indeed, qualitative data of DS are 317 coherent with the delay observed. For example, the comparison of the HPG with different DS 318 shows that $\mathrm{t}_{\mathrm{CH}}(\mathrm{HPG} 1)>\mathrm{t}_{\mathrm{CH}}(\mathrm{HPG} 2)>\mathrm{t}_{\mathrm{CH}}(\mathrm{HPG} 3)$ with $\mathrm{DS}(\mathrm{HPG} 1)<\mathrm{DS}(\mathrm{HPG} 2)<\mathrm{DS}(\mathrm{HPG} 3)$.

319 Moreover, delay induced by HPG 4 is slightly higher compared to HPG 5 and 6 . The only 320 difference between these HPG is the substitution of the alkyl chains which could cause steric 321 hindrance and increase the lipophilic character of the polymer. The presence of alkyl chains 322 could reduce slightly the adsorption and so the delay. Effectively, $\mathrm{t}_{\mathrm{CH}}(\mathrm{HPG} 4)$ is higher than $323 \mathrm{t}_{\mathrm{CH}}(\mathrm{HPG}$,6). Nevertheless, the length of the alkyl chains seems to not affect the adsorption 324 because the difference on hydration delay is negligible. Indeed, the portlandite precipitation times for HPG 5 and HPG 6 are very close. 
327 The effect of the admixture predissolution on the cement hydration kinetics has also been 328 observed. Firstly, this effect in concentrated paste was studied by isothermal calorimetry. 329 Heat evolutions within $24 \mathrm{~h}$ for cement pastes without and with admixtures are presented in 330 Fig. 9. For admixed cement pastes, HPG 1 (a), HPG 2 (b) and HPG 3 (c) were predissolved or 331 not.
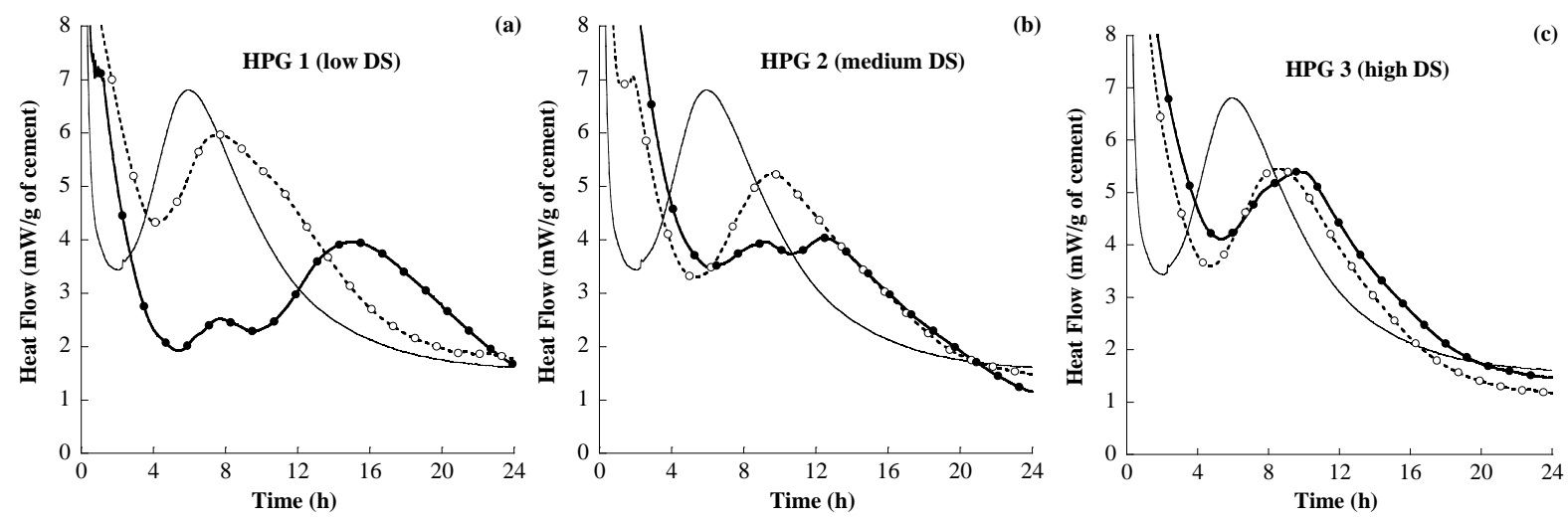

Fig. 9: Isothermal calorimetry curves of cement pastes in presence of HPG 1 (a), HPG 2 (b) and HPG 3 (c) ( - : control; - - O- - : without predissolution; : with admixture predissolution).

Two significant heat flow maxima are observed at early age for the neat cement paste. According to many authors [47-50], the main peak is attributed to the alite hydration reaction. The second peak, only visible as a shoulder, corresponds to renewed dissolution of $\mathrm{C}_{3} \mathrm{~A}$ once

338 the solid gypsum has been exhausted. For the cement pastes admixed with HPG and without predissolution, the main peak is delayed, whatever the admixture. Thus, HPG retard cement hydration at early age, as well in concentrated cement pastes as in diluted suspensions.

341 The polymer predissolution seems to allow the separation of the main peak into two peaks.

342 This separation is more easily visible in the case of the HPG 1 (Fig. 9a). For HPG 4, 5 and 6,

343 which have a high DS, the effect is very weak, as for the HPG 3 (Fig. 9c). For HPG 2 (Fig. 3449 b), which has an intermediate DS, separation of the peak is less pronounced than in the case 
of HPG 1, but it is clearly visible. This suggests that the effect is all the more significant since

346 the DS is low. Thus, HPG act preferentially either on the alite hydration or on the exhaustion

347 of the solid gypsum, which is highlighted when HPG are already in the solution.

348 In diluted suspensions, negligible impact of predissolution is observed in water whatever the 349 admixture considered (Fig. 10a). However, in lime suspension (Fig. 10b), the impact of 350 predissolution is very strong for HPG 1 , with a huge increase in portlandite precipitation time 351 of $77 \%$. As observed by isothermal calorimetry, the effect decreases when the DS increases: + $19 \%$ for HPG 2 and $+10 \%$ for HPG 3 . The impact of predissolution is negligible for HPG 4 and 5. For CE, no impact of predissolution is observed too, which is coherent with results of 354 Pourchez [51]. For HPG, the delay caused by the polymer is more important after 355 predissolution in $20 \mathrm{mM}$ lime solution than in water (no effect), mainly when DS is low. It is 356 therefore an effect of the alkalinity of the medium.
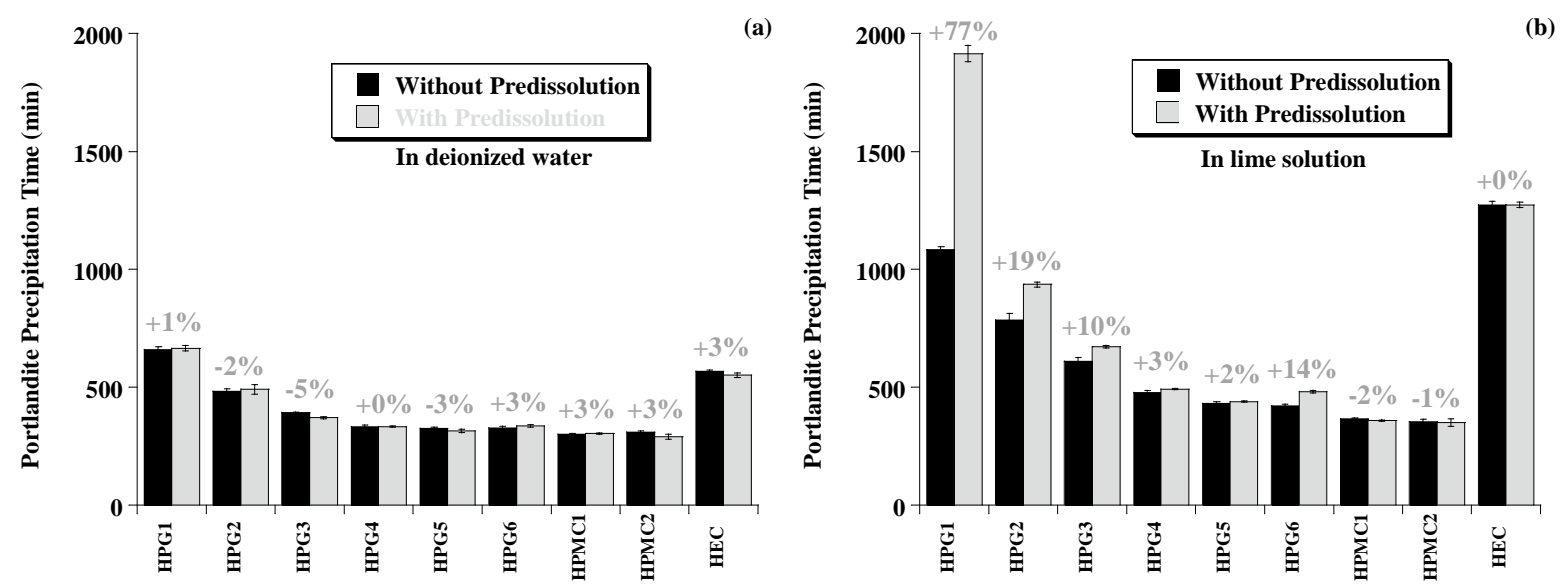

Fig. 10: Effect of predissolution of the polymer on portlandite precipitation time in diluted suspensions with $\mathrm{L} / \mathrm{S}=20$ and $\mathrm{P} / \mathrm{C}=2 \%$ (a: deionized water; $\mathrm{b}$ : $20 \mathrm{mM}$ lime solution).

Different hypotheses can be considered. The polymer could be degraded due to the high 361 alkalinity reached when cement dissolves. This degradation could lead to the formation of carboxylates by peeling reaction, molecules known to have a strong retarding effect [52]. The predissolution in lime would promote this degradation, resulting in an increase in the delay. 
364 Ultra-violet spectroscopy allows highlighting alkaline degradation. Indeed, the alkaline 365 degradation of sugars leads to the formation of a large peak in the UV range, between 250 and $366300 \mathrm{~nm}$, due to the formation of saccharinic acids or the enolization of the sugars [12]. To 367 investigate this effect, HPG and sugars (samples tested in calcium binding experiments) were 368 stirred in water and lime solution. UV-Vis absorption spectra were carried out over time. Fig. 36911 shows these results in case of HPG 1 and galactose, representing HPG and sugars respectively. In the case of HPG 1, the absorption spectra are different in water and in lime 371 solution. Nevertheless, the difference is almost instantaneous and then remains stable over 372 time. Therefore, it cannot be due to alkaline degradation. The difference in intensity is only 373 due to HPG dissolution. For the other 5 HPG, no difference was observed between UV-Vis 374 absorption spectra of polymer dissolved in water and in lime solution. On the contrary, sugars 375 exhibit actually alkaline degradation. A new peak appears and grows with time when they are dissolved in lime solution.
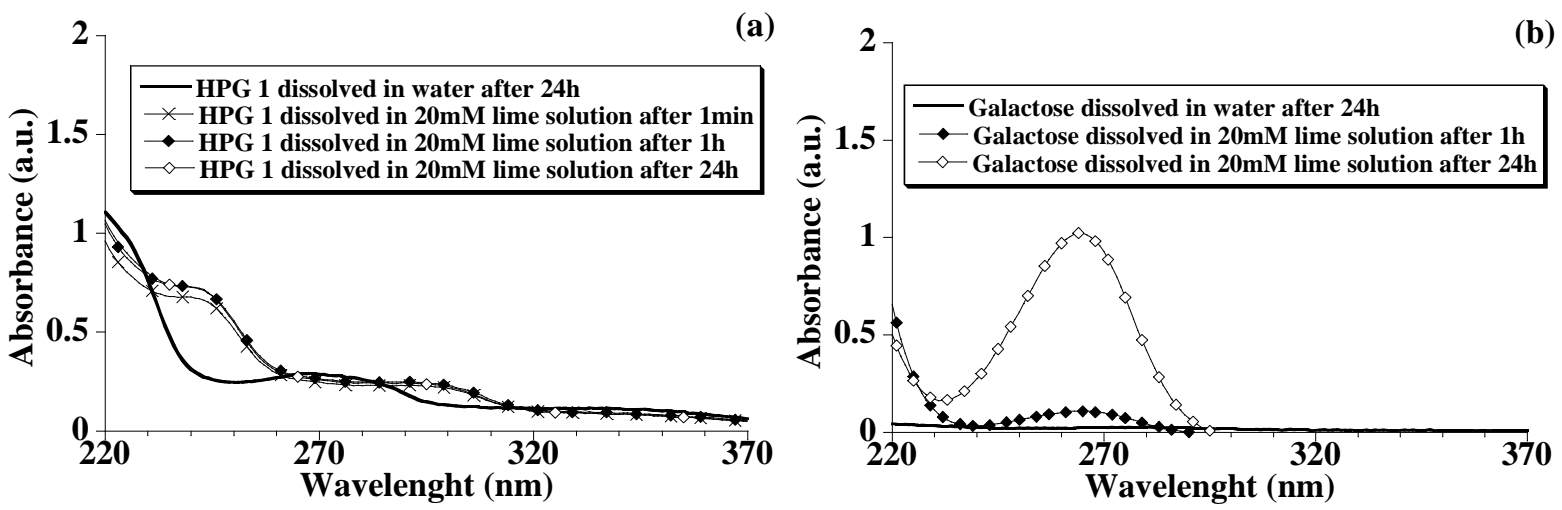

Fig. 11: Effect of dissolution media on UV-Vis absorption spectra of HPG 1 (a) and galactose (b).

379 Moreover, an infrared investigation was made to determine if carboxylates are formed after dissolution of HPG in alkaline media. As above, HPG were stirred in water and lime solution.

381 After $24 \mathrm{~h}$, solutions were neutralized and then placed in an oven until evaporation of the 
382 liquid phase. Solid residues were analyzed by infrared spectrometry. No band at $1590 \mathrm{~cm}^{-1}$,

383 corresponding to carboxylates functions, was observed, neither in water nor in lime solution.

384 Thus, experiments on HPG indicate their alkaline stability. This is consistent with the 385 hypotheses of many authors. A reduction in intrinsic viscosity has been observed for 386 galactomannans under alkaline conditions [53-55]. However, according to these authors, this 387 reduction is not due to degradation by a peeling reaction, but to inhibition of intermolecular 388 interactions (hyperentanglement) because of ionization of hydroxyl groups. Izaguirre et al. 389 reached the same conclusion with HPG [29]. Furthermore, similar results of polysaccharide 390 alkaline stability were observed with CE [42].

391 A second hypothesis would be slower dissolution kinectis of the polymer in lime solution than 392 in water. In that case, in lime solution, the polymer is not fully active to delay the cement 393 hydration without predissolution because the dissolution would be slowdown. On the 394 contrary, predissolution leads to the complete dissolution of the polymer and therefore a 395 maximum delay. In water, if the dissolution is fast, predissolution could have no effect. Fig. 39612 presents the effect of the media on the dissolution kinetics for HPG 1. Dissolution is very 397 fast, both in water and in $20 \mathrm{mM}$ lime solution. The polymer seems to be completely 398 dissolved after $40 \mathrm{~min}$, whatever the dissolution media. Same results are obtained for the 399 other HPG. Thus, dissolution kinetics cannot be responsible for the predissolution effect on 400 cement hydration kinetics. Moreover, guar gum is known to be easily soluble [56]. 


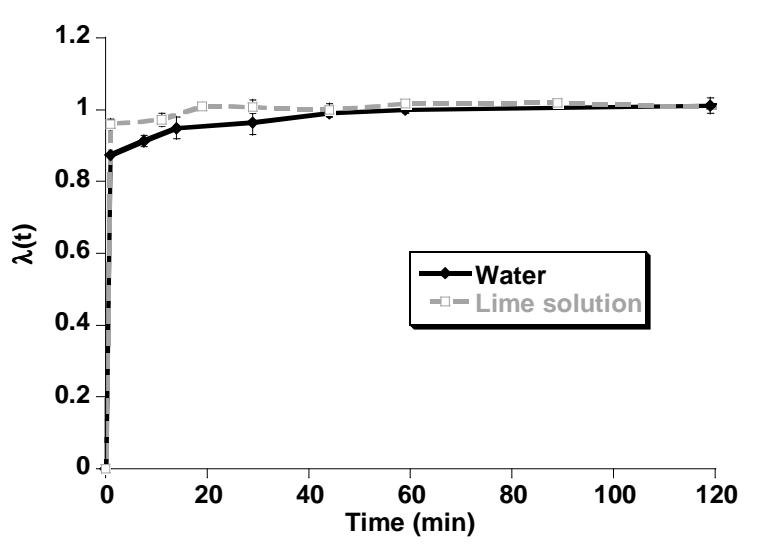

Fig. 12: Dissolution kinetics in water and in 20mM lime solution of HPG 1 at $2 \mathrm{~g} / \mathrm{L}$.

405 According to some authors, hydroxyl groups of galactomannans [53-55] and HPG [29] would

406 ionize in alkaline media. It seems very probable that predissolving the polymer in the lime 407 solution would ionize a maximum of hydroxyl groups and thus enhance the adsorption of 408 polysaccharide on the cement phases. So, the delayed effect is greater after predissolution in 409 lime solution, but there is no change after predissolution in water. That would explain why 410 HPG 1, which is the polymer with the lower DS, thus higher amount of polysaccharidic 411 backbone hydroxyl groups, is the most sensitive to predissolution. Furthermore, this 412 hypothesis is coherent with the adsorption mechanism via the hydroxyl sites proposed to 413 explain hydration delay induced by HPG. This is consistent with the effect of HPG 414 predissolution in water observed by isothermal calorimetry too. Indeed, calorimetry 415 experiments were made in concentrated pastes. The paste is quickly saturated in lime and the $416 \mathrm{pH}$ increases almost instantly. Thus, even if the polymer is predissolved in water, phenomena 417 occurring are closer to what was observed in conductivity experiments after predissolution in 418 lime solution. 


\section{Conclusions}

420 Based upon this study, it appears that HPG delayed cement hydration with an influence on the 421 growth of the hydrates, rather than on the germination of hydrates. Complexation of calcium 422 ions does not explain this effect. A strong impact of the concentration on the hydration 423 kinetics was observed. The results and the molecular similarity with CE suggest that the delay 424 effect is due to the adsorption of the HPG via the interaction between hydroxyl groups and the 425 highly polar hydrated phases. This hypothesis is coherent with the qualitative data of DS.

426 An increase in portlandite precipitation time was noticed after predissolution of HPG in lime 427 solution. It was shown that no alkaline degradation of HPG occurs. Moreover, no difference 428 of admixture dissolution kinetics in water or lime solution was observed. Thus, these two 429 phenomena are not responsible for the increase in the delay. We put forward that the 430 ionization of hydroxyl groups in alkaline media enhances the delay. This is consistent with 431 the adsorption theory. In addition, calorimetric investigations on predissolution effect show 432 that the delayed effect induced by HPG would be more specific on silicate or aluminate 433 reaction.

434 Finally, this paper initiates the study of the interaction between cement and HPG. This 435 polymer, whose study is very scarce in literature, presents very interesting properties. 436 Especially, water retention properties are comparable to those obtained with $\mathrm{CE}$, with the 437 advantage of producing lower pollution during the manufacturing. Therefore, it is very 438 important to improve knowledge of the impact of HPG on cement hydration kinetics.

\section{Acknowledgments}

440 The authors would like to acknowledge Lamberti S.p.A. for the provided products. 


\section{References}

443 [1] L. Bertrand, S. Maximilien, R. Guyonnet, Wedge Splitting Test: A test to measure the 444 polysaccharide influence on adhesion of mortar on its substrate, Proceedings of the 11th 445 International Congress on Polymers in Concrete, Berlin, Germany (2004) 569-576.

446 [2] A. Jenni, L. Holzer, R. Zurbriggen, M. Herwegh, Influence of polymers on microstructure 447 and adhesive strength of cementitious tile adhesive mortars, Cem. Concr. Res. 35 (1) (2005) $448 \quad 35-50$.

449 [3] L. Patural, P. Marchal, A. Govin, P. Grosseau, B. Ruot, O. Devès, Cellulose ethers 450 influence on water retention and consistency in cement-based mortars, Cem. Concr. Res. $451 \quad 41(1)(2011) 46-55$.

452 [4] H. B. Wagner, Polymer modification of portland-cement systems, Chemtech 3 (2) (1973), $453 \quad 105-108$

454 [5] V. A. Ghio, P. J. M. Monteiro, L. A. Demsetz, The rheology of fresh cement paste 455 containing polysaccharide gums, Cem. Concr. Res. 24 (2) (1994) 243-249.

456 [6] K. H. Khayat, Effect of antiwashout admixtures on fresh concrete properties, ACI Mater. J. 92 (2) (1995) 164-171.

458 [7] K. H. Khayat, A. Yahia, Effect of welan gum-high-range water reducer combinations on 459 rheology of cement grout, ACI Mater. J. 94 (5) (1997) 365-372.

460 [8] H. Paiva, L. M. Silva, J. A. Labrincha, V. M. Ferreira, Effects of a water-retaining agent 461 on the rheological behaviour of a single-coat render mortar, Cem. Concr. Res. 36 (7) (2006) $462 \quad 1257-1262$.

463 [9] J. Plank, Applications of biopolymers and other biotechnological products in building 464 materials, Appl. Microbiol. Biotechnol. 66 (1) (2004) 1-9. 
465 [10] Y. Chen, X. Wu, X. Miao, J. Luo, B. Jiang, Determination of the degree of substitution 466 of hydroxypropyl guar gum at C-6 by Pyrolysis-Gas Chromatography spectrometry, 467 Carbohyd. Polym. 82 (3) (2010) 829-832.

468 [11] J. F. Young, A review of the mechanisms of the set-retardation in portland cement pastes 469 containing organic admixtures, Cem. Concr. Res. 2 (4) (1972) 415-433.

470 [12] N. L. Thomas, J. D. Birchall, The retarding action of sugars on cement hydration, Cem. 471 Concr. Res. 13 (6) (1983) 830-842.

472 [13] J. H. Taplin, Discussion of "Some chemical additions and admixtures in cement paste 473 and concrete" by H.E. Vivian, Proceedings of the 4th Internationnal Congress on the 474 Chemistry of Cement, Washington, 7 (1) (1962) 909-926.

475 [14] G. M. Bruere, Set-retarding effects of sugars in Porland cement pastes, Nature 212 476 (1966) 502-503.

477 [15] N. B. Singh, Effect of gluconates on the hydration of cement, Cem. Concr. Res. 6 (1976) $478 \quad 455-460$.

479 [16] J. D. Birchall, N. L. Thomas, The mechanism of retardation of setting of OPC by sugars, 480 Proceedings of British Ceramic Proceedings, London, 35 (1984) 305-315.

481 [17] M. C. Garci Juenger, H. M. Jennings, New insights into the effects of sugar on the 482 hydration and microstructure of cement pastes, Cem. Concr. Res. 32 (3) (2002) 393-399.

483 [18] V. K. Peterson, M. C. Garci Juenger, Time-resolved quasielastic neutron scattering study 484 of the hydration of tricalcium silicate: effects of $\mathrm{CaCl} 2$ and sucrose, Phys. Rev. B 385-386 (1) 485 (2006) 222-224.

486 [19] L. Zhang, L. J. J. Catalan, R. J. Balec, A. C. Larsen, H. H. Esmaeili, S. D. Kinrade, 487 Effects of saccharide set retarders on the hydration of ordinary portland cement and pure 488 tricalcium silicate, J. Am. Ceram. Soc. 93 (1) (2010) 279-287. 
[20] M. Alesiani, S. Capuani, R. Giorgi, B. Maraviglia, I. Pirazzoli, F. Ridi, P. Baglioni, 490 Influence of cellulosic additives on tricalcium silicate hydration: nuclear magnetic resonance 491 relaxation time analysis, J. Phys. Chem. B 108 (15) (2004) 4869-4874.

492 [21] A. M. Betioli, P. J. P. Gleize, D. A. Silva, V. M. John, R. G. Pileggi, Effect of HMEC on 493 the consolidation of cement pastes: Isothermal calorimetry versus oscillatory rheometry, Cem. 494 Concr. Res. 39 (5) (2009) 440-445.

495 [22] E. Knapen, D. Van Gemert, Cement hydration and microstructure formation in the 496 presence of water-soluble polymers, Cem. Concr. Res. 39 (1) (2009) 6-13.

497 [23] F. Ridi, E. Fratini, F. Mannelli, P. Baglioni, Hydration process of cement in the presence 498 of a cellulosic additive. A calorimetric investigation, J. Phys. Chem. B 109 (30) (2005) 499 14727-14734.

500 [24] D. A. Silva, P. J. M. Monteiro, The influence of polymers on the hydration of portland 501 cement phases analyzed by soft X-ray transmission microscopy, Cem. Concr. Res. 36 (8) 502 (2006) 1501-1507.

503 [25] H. J. Weyer, I. Müller, B. Schmitt, D. Bosbach, A. Putnis, Time-resolved monitoring of 504 cement hydration: Influence of cellulose ethers on hydration kinetics, Nucl. Instrum. Meth. B $505238(1-4)(2005) 102-106$.

506 [26] A. Peschard, A. Govin, P. Grosseau, B. Guilhot, R. Guyonnet, Effect of polysaccharides 507 on the hydration of cement paste at early ages, Cem. Concr. Res. 34 (11) (2004) 2153-2158.

508 [27] J. Pourchez, A. Peschard, P. Grosseau, R. Guyonnet, B. Guilhot, F. Vallée, HPMC and 509 HEMC influence on cement hydration, Cem. Concr. Res. 36 (2) (2006) 288-294.

510 [28] J. Pourchez, P. Grosseau, R. Guyonnet, B. Ruot, HEC influence on cement hydration 511 measured by conductometry, Cem. Concr. Res. 36 (9) (2006) 1777-1780. 
512 [29] A. Izaguirre, J. Lanas, J. I. Álvarez, Characterization of aerial lime-based mortars 513 modified by the addition of two different water-retaining agents, Cem. Concr. Comp. 33 (2) $514 \quad$ (2011) 309-318.

515 [30] D. Risica, M. Dentini, V. Crescenzi, Guar gum methyl ethers. Part I. Synthesis and 516 macromolecular characterization, Polymer 46 (26) (2005) 12247-12255.

517 [31] B. Biasotti, M. Giudici, V. Langella, U. Pfeiffer, Highly substituted hydroxypropylguar: 518 a strong contribution to construction chemistry, Proceedings of the Third International 519 Drymix Mortar Conference, Nürnberg, Germany (2011).

520 [32] Standard C1506-09, Standard test Method for Water Retention of Hydraulic Cement521 Based Mortars and Plasters. Am. Soc. Test. Mat. (2009).

522 [33] EN 196-1, Methods of testing cement — Part 1: Determination of strength (2006).

523 [34] A. Nonat, J. C. Mutin, X. Lecoq, S. P. Jiang, Physico-chemical parameters determining 524 hydration and particle interactions during the setting of silicate cements, Solid State Ionics 525 101-103 (2) (1997) 923-930.

526 [35] D. Damidot, A. Nonat, P. Barret, Kinetics of Tricalcium Silicate Hydration in Diluted 527 Suspensions by Microcalorimetric Measurements, J. Am. Ceram. Soc. 73 (11) (1990) 33195283322.

529 [36] C. Comparet, A. Nonat, S. Pourchet, J. P. Guicquero, E. Gartner, Chemical interaction of 530 di-phosphonate terminated monofunctional polyoxethylene superplasticizer with hydrating 531 tricalcium silicate, Proceedings of the 6th CANMET/ACI International Conference on 532 Superplasticizers and Other Chemical Admixtures in Concrete (1997) 61-74.

533 [37] V. S. Ramachandran, M. S. Lowery, Conduction calorimetric investigation of the effect 534 of retarders on the hydration of Portland cement, Thermochim. Acta 195 (1992) 373-387. 535 [38] NF DTU 26.1, Travaux d'enduits de mortiers (2008). 
536 [39] S. Garrault, A. Nonat, Y. Sallier, L. Nicoleau, On the origin of the dormant period of 537 cement hydration », Proceedings of the 13th International Congress on the Chemistry of 538 Cement, Madrid, Spain (2011).

539 [40] J. Pourchez, P. Grosseau, B. Ruot, Changes in C3S hydration in the presence of cellulose 540 ethers, Cem. Concr. Res. 40 (2) (2010) 179-188.

541 [41] J. Cheung, A. Jeknavorian, L. Roberts, D. Silva, Impact of admixtures on the hydration 542 kinetics of Portland cement, Cem. Concr. Res. 41 (12) (2011) 1289-1309.

543 [42] J. Pourchez, A. Govin, P. Grosseau, R. Guyonnet, B. Guilhot, B. Ruot, Alkaline stability 544 of cellulose ethers and impact of their degradation products on cement hydration, Cem. 545 Concr. Res. 36 (7) (2006) 1252-1256.

546 [43] C. Jolicoeur, M. A. Simard, Chemical admixture-cement interactions: Phenomenology 547 and physico-chemical concepts, Cem. Concr. Comp. 20 (2-3) (1998) 87-101.

548 [44] J. Pourchez, P. Grosseau, B. Ruot, Current understanding of cellulose ethers impact on 549 the hydration of C3A and C3A-sulphate systems, Cem. Concr. Res. 39 (8) (2009) 664-669.

550 [45] J. Wang, P. Somasundaran, D. R. Nagaraj, Adsorption mechanism of guar gum at solid551 liquid interfaces, Min. Eng. 18 (1) (2005) 77-81.

552 [46] J. Wang, P. Somasundaran, Study of galactomannose interaction with solids using AFM, 553 IR and allied techniques, J. Colloid Interf. Sci. 309 (2) (2007) 373-383.

554 [47] H. Minard, S. Garrault, L. Regnaud, A. Nonat, Mechanisms and parameters controlling 555 the tricalcium aluminate reactivity in the presence of gypsum, Cem. Concr. Res. 37 (10) 556 (2007) 1418-1426.

557 [48] C. Hesse, F. Goetz-Neunhoeffer, et J. Neubauer, A new approach in quantitative in-situ 558 XRD of cement pastes: Correlation of heat flow curves with early hydration reactions, Cem. 
560 [49] J. W. Bullard, H. M. Jennings, R. A. Livingston, A. Nonat, G. W. Scherer, J. S.

561 Schweitzer, K. L. Scrivener, J. J. Thomas, Mechanisms of cement hydration, Cem. Concr. 562 Res. 41 (12) (2011) 1208-1223.

563 [50] A. Quennoz, K. L. Scrivener, Hydration of C3A-gypsum systems, Cem. Concr. Res. 42 564 (7) (2012) 1032-1041.

565 [51] J. Pourchez, « Aspects physico-chimiques de l'interaction des éthers de cellulose avec la 566 matrice cimentaire », PhD Thesis, Ecole Nationale Supérieure des Mines de Saint-Etienne 567 (2006) $285 \mathrm{p}$.

568 [52] Y. Ohama, Polymer-based admixtures, Cem. Concr. Comp. 20 (2-3) (1998) 189-212.

569 [53] E. R. Morris, A. N. Cutler, S. B. Ross-Murphy, D. A. Rees, J. Price, Concentration and 570 shear rate dependence of viscosity in random coil polysaccharide solutions, Carbohyd. Polym. $571 \quad 1(1)(1981) 5-21$.

572 [54] F. M. Goycoolea, E. R. Morris, M. J. Gidley, Viscosity of galactomannans at alkaline 573 and neutral pH: evidence of 'hyperentanglement' in solution, Carbohyd. Polym. 27 (1) (1995) $574 \quad 69-71$.

575 [55] J. P. Doyle, G. Lyons, E. R. Morris, New proposals on "hyperentanglement" of 576 galactomannans: Solution viscosity of fenugreek gum under neutral and alkaline conditions, 577 Food Hydrocolloid. 23 (6) (2009) 1501-1510.

578 [56] P. A. Dakia, B. Wathelet, M. Paquot, Influence de la teneur en galactose sur les 579 interactions moléculaires et sur les propriétés physico-chimiques des galactomannanes en 580 solution, Biotechnol. Agron. Soc. Environ. 14 (1) (2010) 213-223. 